\title{
Case report. Een benigne zwelling van de testis: een intratesticulaire epidermoïdcyste. Cave: overige echografische afwijkingen
}

\author{
Thomas B. R. M. Sterenborg' • Irene M. Tjiam² · Willem Vreuls³ • Diederick Duijvesz'
}

Published online: 6 November 2018

(c) The Author(s) 2018

\section{Samenvatting}

Deze casus betreft een 22-jarige patiënt die zich presenteerde met een niet-pijnlijke, palpabele zwelling van de linker testis. Echografie toonde een typisch beeld met uienringen, met daarnaast een tweetal kleine hypo-echogene laesies als toevalsbevinding. Patiënt onderging daarom een radicale orchidectomie links. Pathologie bevestigde de diagnose 'intratesticulaire epidermoïdcyste', er werd echter ook een seminoom gevonden. Een intratesticulaire epidermoïdcyste is de meest voorkomende afwijking van de testis. Echografie is eerste keus in de diagnostiek, maar hiermee kan de diagnose niet met zekerheid worden gesteld, aangezien een matuur teratoom dezelfde echografische kenmerken kan hebben. Indien er sprake is van alleen een epidermoïdcyste zou kunnen worden volstaan met een afwachtend beleid of een partiële resectie. In het kader van deze casus was een radicale orchidectomie achteraf de juiste keuze, aangezien er ook sprake was van een seminoom.

Trefwoorden intratesticulaire epidermoïdcyste $\cdot$ testis $\cdot$ benigne

\section{Case report. A benign tumor of the testis: an intratesticular epidermoid cyst. Preserve you from other ultrasound abnormalities}

\begin{abstract}
A 22-year-old patient visited our outpatient clinic with a non-painful, palpable swelling of the left testis. Ultrasonography showed suspicion of an intratesticular epidermoid cyst with a hypoechogenic lesion located next to it. The patient underwent a radical orchiectomy. Pathology showed an intratesticular epidermoid cyst and also a small seminoma. An intratesticular epidermoid cyst is the most seen, benign abnormality of the testis. Ultrasound of the testis is the first choice of diagnostics and shows a characteristic onion ring like pattern. Treatment options are follow-up or partial resection. In this specific case, a radical orchiectomy was the good choice because of the seminoma found in the specimen.
\end{abstract}

Keywords intratesticular epidermoid cyst $\cdot$ testis $\cdot$ benign

\section{Introductie}

Een zwelling van het scrotum is een afwijking die dagelijks in de praktijk beoordeeld wordt (bijvoorbeeld een hydrocele

drs. Diederick Duijvesz

d.duijvesz@cwz.nl

1 afdeling Urologie, Canisius Wilhelmina Ziekenhuis, Nijmegen, Nederland

2 afdeling Urologie, HagaZiekenhuis, Den Haag, Nederland

3 afdeling Pathologie, Canisius Wilhelmina Ziekenhuis, Nijmegen, Nederland of spermatocele). Bij 782 mannen werd in 2017 de diagnose testiscarcinoom gesteld [1]. Differentiatie tussen benigne en maligne afwijkingen gebeurt in eerste instantie op basis van anamnese, lichamelijk onderzoek, laboratorium- en radiologisch onderzoek. Indien een afwijking verdacht is voor maligniteit, moet er pathologisch-anatomisch onderzoek verricht worden op weefsel dat is verkregen middels radicale excisie dan wel biopsie. In deze casus presenteren wij een patiënt met een benigne afwijking van de testis die klinisch verdacht was voor een maligniteit vanwege de overige echografische afwijkingen. 


\section{Casus}

Een 22-jarige patiënt bezocht onze polikliniek Urologie in verband met een sinds enkele maanden niet-pijnlijke palpabele zwelling van de linkertestis. Hij kon niet goed aangeven of de afwijking gegroeid was. Er was geen sprake geweest van een infectie aan de testis. Bij lichamelijk onderzoek viel op dat de linkertestis een kleiner volume had, met craniaal een ronde palpabele afwijking van ongeveer $1 \mathrm{~cm}$. Rechts waren er geen afwijkingen. Via de huisarts was al een echo scrotum gemaakt, waarop drie laesies in de linkertestis werden gezien. De grootste laesie was rond en scherp afgegrensd, en had een diameter van $12 \mathrm{~mm}$, waarbij er een karakteristiek beeld van onion rings werd gezien. Doppleronderzoek liet geen doorbloeding zien van de grootste laesie (fig. 1). Volgens de radioloog was een maligniteit niet uitgesloten. De kleinere laesies, hypo-echogeen, bedroegen respectievelijk 4 en $3 \mathrm{~mm}$ (fig. 2). Tumormarkers waren niet verhoogd: bèta-humaan choriongonadotrofine (HCG) $<1 \mathrm{U} / \mathrm{L}$, lactaat dehydrogenase (LD) $158 \mathrm{U} / \mathrm{L}$ en alfafoetoproteïne (AFP) $2 \mathrm{kU} / \mathrm{L}$.

Er werd samen met de patiënt besloten om op basis van kliniek en echografie een radicale orchidectomie links te verrichten en, op verzoek van de patiënt, een testisprothese te plaatsen. De gevolgen van deze ingreep op het tes-

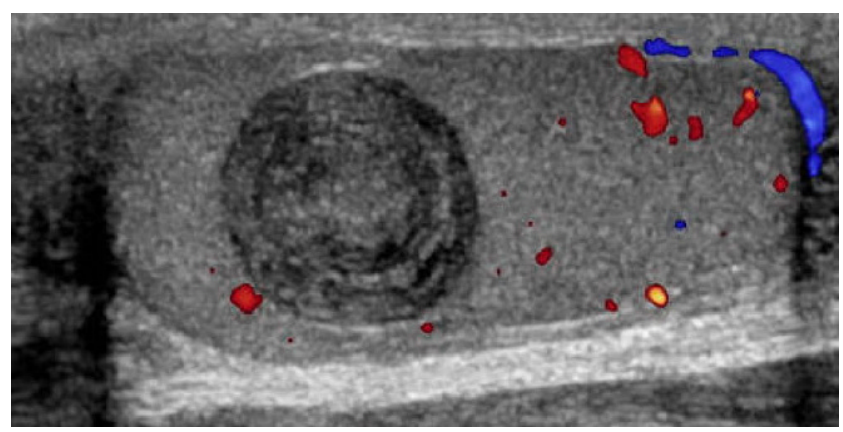

Figuur 1 Echo-doppler van de intratesticulaire epidermoïdcyste. Geen vascularisatie zichtbaar

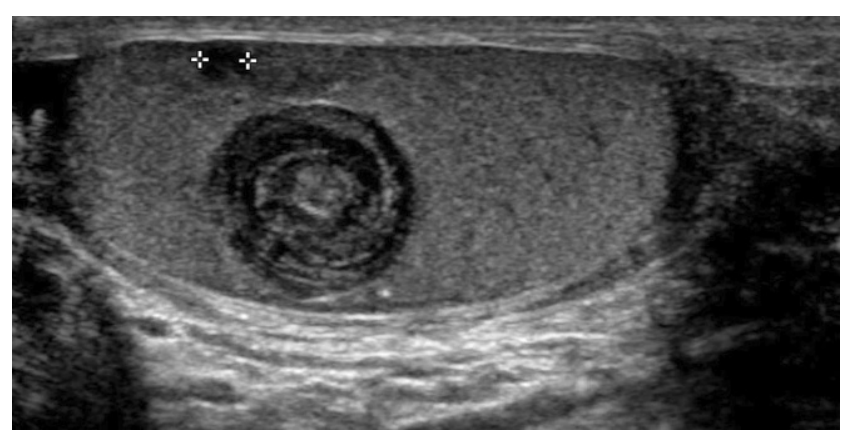

Figuur 2 Linkertestis: ventraal van de intratesticulaire epidermoïdcyste bevindt zich een hypo-echogene afwijking

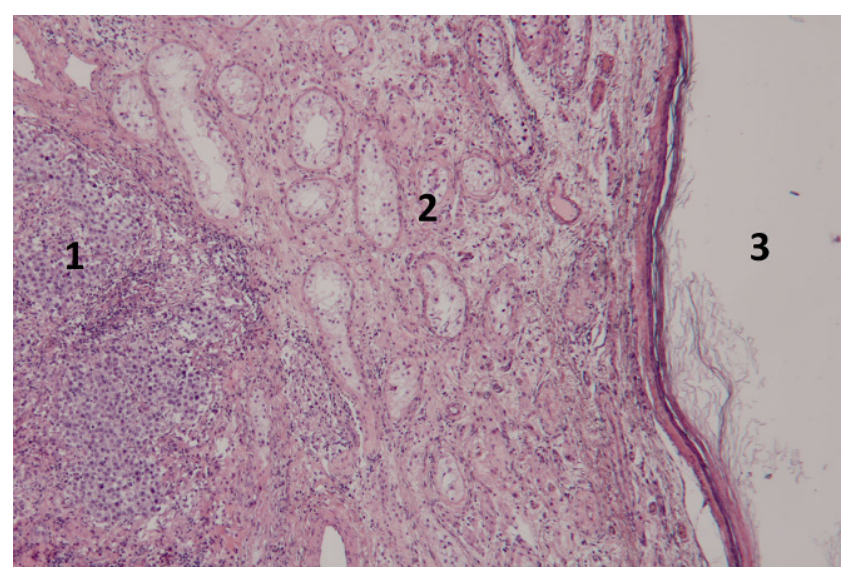

Figuur 3 HE-kleuring. 50× vergroot. Geheel links het seminoom met het typische uitbundige lymfoïde infiltraat (1). In het midden de atrofische tubuli seminiferi met Leydig-cellhyperplasie (2) en geheel rechts de epidermoïdcyste (3)

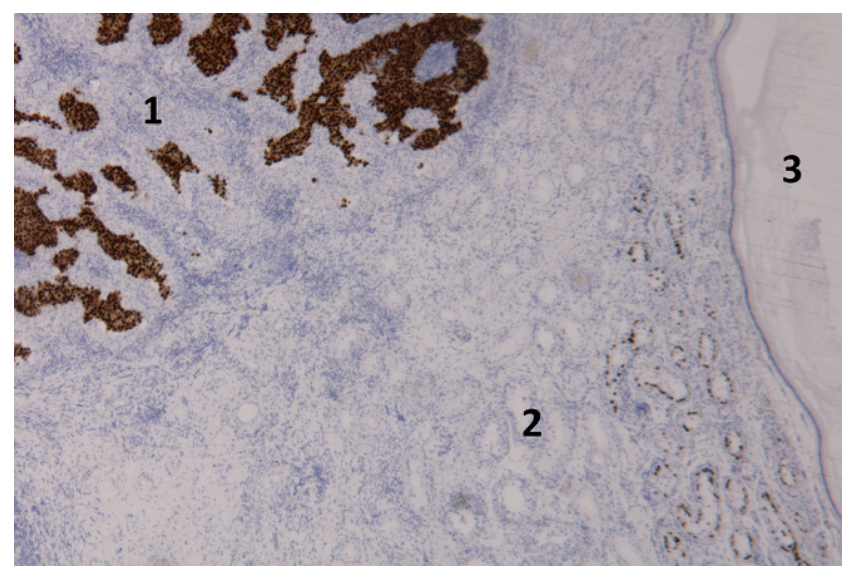

Figuur 4 OCT4 kleuring (marker voor seminoom). Links het seminoom (1). In het midden atrofische tubuli seminiferi met rechts van het midden bruine randaankleuring zoals wordt gezien bij ITGCN (2). Geheel rechts de epidermoïdcyste (3)

tosterongehalte en de semenproductie werden besproken, waarna de patiënt niet koos voor semenpreservatie.

De ingreep verliep ongecompliceerd en peroperatief werden er geen macroscopische afwijkingen gezien. De PAuitslag toonde dat de grootste afwijking een epidermoïdcyste betrof zonder aanwijzingen voor een dermoïdcyste dan wel een matuur teratoom. Daarnaast was er sprake van een kiemceltumor van $0,6 \mathrm{~cm}$, waarvan het beeld paste bij een seminoom zonder angio-invasie, met tevens uitgebreide intratubulaire kiemcelneoplasie (ITGCN; fig. 3 en 4).

Voor publicatie van de casus is informed consent verkregen bij de patiënt. 


\section{Discussie}

Een intratesticulaire epidermoïdcyste ontstaat uit kiemcellijnen, is benigne van aard en betreft ongeveer $1-2 \%$ van alle testistumoren [2,3]. Hoe een epidermoïdcyste ontstaat, is niet geheel duidelijk. Mogelijke hypotheses zijn dat de cyste resulteert uit monodermale ontwikkeling van een teratoom of door metaplasie van oppervlakte-epitheel. In eerste instantie zal een echo gemaakt worden van de testis om de diagnose te kunnen stellen. Intratesticulaire epidermoïdcysten hebben op een echogram een kenmerkend patroon dat lijkt op de opbouw van een uienschil, en bestaat uit echorijke en echoarme 'schillen' [4]. Ondanks het soms karakteristieke beeld op de echo en normale waarden van het bèta-HCG, AFP en LDH is het onderscheid tussen deze afwijking en een maligne testistumor moeilijk te maken. Indien de diagnostiek niet evident of conclusief is, is het mogelijk om een MRI van de testis te verrichten. Op een MRI wordt een typische bulls eye gezien, met centraal een hoge intensiteitszone met squameuze cellen en perifeer keratinevezels. Er is tot op heden te weinig bewijs dat dit van toegevoegde waarde is naast de echografie en laboratoriumonderzoek [5]. Eventueel zou doppleronderzoek van de afwijking kunnen helpen, omdat er in een epidermoïdcyste geen vascularisatie wordt gezien. Differentiaaldiagnostisch moet bij een epidermoïdcyste worden gedacht aan een seminoom, een matuur teratoom of een dermoïdcyste. Zo beschreven Maizlin et al. dat een teratoom dezelfde echografische kenmerken kan hebben als een epidermoïdcyste. In deze studie kwam naar voren dat bij drie van de zes patiënten die echografisch een sterke verdenking hadden op een epidermoïdcyste door de kenmerkende uienschilopbouw, het pathologisch verslag verdacht was voor een teratoom [5]. De behandeling van een epidermoïdcyste wordt in de literatuur uitgebreid bediscussieerd, waarbij voorheen een radicale orchidectomie vaak als behandeling van eerste keuze werd gezien, aangezien aanvullende diagnostiek niet specifiek genoeg was om te differentiëren tussen een benigne of maligne laesie. Aangezien epidermoïdcysten benigne zijn, zou een expectatief beleid met eventueel echografisch vervolgen, behandeling van eerste keuze moeten zijn, zeker als het klinisch beloop dit toelaat [6]. Bij twijfel volstaat een testissparende behandeling [7]. In het kader van testispreservatie voor de fertiliteit en voor het testosteronniveau in de loop van het leven, wordt tegenwoordig aanbevolen te streven naar testissparende therapie indien mogelijk [8,9]. Bij testissparende chirurgie is het advies om, behalve enucleatie van de cyste, ook een vriescoupe in te sturen van het parenchymweefsel en te beoordelen of er geen teratomateuze componenten of (pre)maligne kenmerken aanwezig zijn [10]. Van de tot nu toe gepubliceerde artikelen hebben de patiënten een zeer goede prognose na testissparende chirurgie of radicale orchidectomie [11-14].
In één casus is een recidief epidermoïdcyste beschreven na testissparende chirurgie [15]. Tot op heden is nooit beschreven of er een relatie is tussen een epidermoïdcyste en een (pre)maligne afwijking in de testis.

\section{Terug naar de casus}

Postoperatief was er sprake van een ongecompliceerd beloop en was de patiënt tevreden met de prothese. Behalve de epidermoïdcyste bleek er ook sprake van een klein seminoom. Het voorkomen van dit begeleidend seminoom werd beschouwd als een toevalsbevinding. In het multidisciplinair overleg werd de patiënt besproken en werd er in verband met het seminoom besloten tot disseminatieonderzoek en follow-up volgens de richtlijn.

\section{Conclusie}

Een intratesticulaire epidermoïdcyste is een zeldzame benigne afwijking met een echografisch beeld van 'uienringen'. Ondanks het typische beeld is echografische differentiatie tussen een benigne en maligne afwijking niet altijd goed mogelijk, omdat een matuur teratoom dezelfde echografische kenmerken kan hebben als een epidermoïdcyste. Primair zou moeten worden overwogen om een expectatief beleid te volgen. Indien twijfel over de diagnose bestaat, gaat de voorkeur uit naar het nemen van een biopt, dan wel een peroperatieve vriescoupe om de diagnose epidermoïdcyste te bevestigen. In dat geval kan men volstaan met enucleatie van de cyste in het kader van testispreservatie en is verdere follow-up niet nodig.

Open Access This article is distributed under the terms of the Creative Commons Attribution 4.0 International License (http:// creativecommons.org/licenses/by/4.0/), which permits unrestricted use, distribution, and reproduction in any medium, provided you give appropriate credit to the original author(s) and the source, provide a link to the Creative Commons license, and indicate if changes were made.

\section{Literatuur}

1. Cijfers over het mannelijk geslachtsorgaan. https://www.cijfersoverkanker.nl. Geraadpleegd op 1 juli 2018.

2. Bennett GL, Garcia RA. Benign intratesticular dermoid cyst: sonographic findings. Ajr Am J Roentgenol. 2002;179(5):1315-7.

3. Aguilera Tubet C, Lopez Rasines G, Roca Edreira A, Martín García B, Hernández Rodríguez R, Portillo Martín JA, et al. Testicular epidermoid cyst: uncommon lesion of difficult preoperative diagnosis. Actas Urol Esp. 2005;29(9):905-8.

4. Maizlin ZV, Belenky A, Baniel J, Gottlieb P, Sandbank J, Strauss $\mathrm{S}$. Epidermoid cyst and teratoma of the testis: sonographic and histologic similarities. J Ultrasound Med. 2005;24(10):1403-9. Quiz 1401-1410. 
5. Kim W, Rosen MA, Langer JE, Banner MP, Siegelman ES, Ramchandani P. US MR imaging correlation in pathologic conditions of the scrotum. Radiographics. 2007;27(5):1239-53.

6. Beij JS de, Loopik LS van, Leeuwen MA van, Stapper G, Lock MTWT. Benigne intratesticulaire afwijkingen. Ned Tijdschr Urol. 2006;4:112-22.

7. Vrooman OPJ, Witjes JA, Mus RDM, Hulsbergen-van der Kaa CA, Balken MR van. Epidermoid-cyste van de testis. Ned Tijdschr Urol. 2009;8:204-7.

8. Dinkelman-Smit M, Boellaard WPA, Timmer ER, Casteren NJ van, Dohle GR. Radicaal anders: waarom semencryopreservatie bij mannen met een testistumor moet worden aangeboden vóór de radicale orchiëctomie. Tijdschr Urol. 2016;6:97-103.

9. Richtlijn Testiscarcinoom $\rightarrow$ Diagnostiek $\rightarrow$ Voorlichting. https:// www.oncoline.nl. Geraadpleegd op 1 juli 2018.

10. Huyghe E, Mazerolles C, Moran C, Khedis M, Khoury E, Nohra $\mathrm{J}$, et al. Synchronous epidermoid cyst and mature teratoma of the testis: an unusual association. Urol Int. 2007;78(4):364-6.

11. Heidenreich A, Zumbe J, Vorreuther R, Klotz T, Vietsch H, Engelmann UH. Testicular epidermoid cyst: orchiectomy or enucleation resection? Urologe A. 1996;35(1):1-5.
12. Dieckmann KP, Loy V. Epidermoid cyst of the testis: a review of clinical and histogenetic considerations. $\mathrm{Br} \mathrm{J}$ Urol. 1994;73(4):436-41.

13. Shah KH, Maxted WC, Chun B. Epidermoid cysts of the testis: a report of three cases and an analysis of 141 cases from the world literature. Cancer. 1981;47(3):577-82.

14. Metcalfe PD, Farivar-Mohseni H, Farhat W, McLorie G, Khoury A, Bagli DJ. Pediatric testicular tumors: contemporary incidence and efficacy of testicular preserving surgery. J Urol. 2003;170(6 Pt 1):2412-5. Discussion 2415-2416.

15. Friend J, Barker A, Khosa J, Samnakay N. Benign scrotal masses in children - some new lessons learned. J Pediatr Surg. 2016;51(10):1737-42.

drs. Thomas B.R.M. Sterenborg uroloog

dr. Irene M. Tjiam uroloog

drs. Willem Vreuls patholoog

drs. Diederick Duijvesz uroloog 